\title{
INTERFACE ENTRE SEGURANÇA PÚBLICA E SEGURANÇA PRIVADA NO BRASIL: CONCORRÊNCIA OU COMPLEMENTARIEDADE?
}

\author{
Giovani Clarck* \\ Sérgio Augusto Veloso Brasil**
}

\section{RESUMO}

Cabe aos órgãos de segurança pública atuar de forma preventiva e repressiva para preservação da ordem pública. As atividades de segurança privada são reguladas, autorizadas e fiscalizadas pela Polícia Federal, no Brasil, sendo complementares às atividades de segurança pública. O problema de pesquisa refere-se à existência, ou não, de um planejamento estatal que incentive a atividade de segurança privada. $\mathrm{O}$ método adotado foi qualitativo do tipo exploratório, com fulcro na legislação vigente sobre a segurança pública e privada. Constatouse que não há comprovação da existência de um planejamento estatal objetivando enfraquecer a segurança pública, que é direito fundamental do cidadão.

Palavras-chave: Ordem Pública. Segurança Pública. Segurança Privada. Planejamento. Atividades de segurança.

\section{INTERFACE BETWEEN PUBLIC SAFETY AND SECURITY PROVEN IN BRAZIL: COMPETITION OR COMPLEMENTARY?}

\begin{abstract}
Public security bodies are responsible for acting in a preventive and repressive manner to preserve public order. Private security activities are regulated, authorized and supervised by the Federal Police in Brazil, being complementary to public security activities. The research problem refers to the existence, or not, of state planning that encourages private security activity. The adopted method was qualitative of the exploratory type, based on the current legislation on public and private security. It was found that there is no evidence of the existence of state planning aimed at weakening public security, which is a fundamental right of the citizen.
\end{abstract}

Keywords: Public order. Public security. Private security. Planning. Security activities.

\section{INTRODUÇÃO}

A demanda do homem por segurança vem desde os primórdios da história da humanidade. Desde muito se busca a proteção da integridade física frente a ataques de

\footnotetext{
* Professor da Faculdade de Direito da UFMG, Professor do Programa de Pós-Graduação em Direito da PUC Minas, Doutor em Direito Econômico pela UFMG. E-mail: giovaniclark@gmail.com

${ }^{* *}$ Doutorando em Direito Público pela PUC Minas. Mestre em Direito Empresarial pela Faculdade de Direito Milton Campos. Especialista em Segurança Pública pela Escola de Governo João Pinheiro. Formado no Curso de Altos Estudos de Política e Estratégia da Escola Superior de Guerra. E-mail: sergioavbrasil@gmail.com
} 
animais selvagens e outras tribos hostis. Seja qual for a causa do embate, luta pela sobrevivência, por território, ou outros motivos, houve uma evolução nas estratégias de defesa e ataque com o fito de se manter a integridade física e patrimonial.

Com o passar do tempo e a criação do Estado, aqueles guerreiros ou cavaleiros nobres, que antes eram livres, passam a receber salário pelos seus préstimos e subordinam-se ao suserano. A sociedade progride para um Estado moderno, que se caracteriza pela divisão do trabalho e monopolização da tributação e da violência física. Dessa feita, o Estado passa de monopólio pessoal de um único indivíduo, caracterizado na monarquia absoluta, para um monopólio público e acaba sendo institucionalizado. A partir do estabelecimento de regras de convivência e com o surgimento das Constituições, com um conjunto de normas que regulam a convivência do homem, inclusive de ordem econômica, o Direito se modifica e se transforma, de instrumento de harmonização de conflitos e legitimação do poder, em instrumento de implementação de políticas públicas.

No caso brasileiro, com o advento da Constituição de 1988 (CRFB/88), o país teve mudanças sociais significativas, com revigoramento dos direitos de cidadania e especial atenção ao princípio da dignidade humana. Com isso, o Estado deve planejar sua atuação na busca da harmonia de interesses públicos e privados para manter a paz social. Especificamente os órgãos de segurança pública na estrutura do Estado têm papel fundamental na concatenação desse conflito de interesses. O art. 144 da CRFB/88 estabelece que a segurança pública é dever do Estado, direito e responsabilidade de todos, exercida para a preservação da ordem pública e da incolumidade das pessoas e do patrimônio, com a atuação de seus respectivos órgãos (BRASIL, 1988).

A presente contribuição propicia a reflexão sobre a importância das políticas públicas e o planejamento estatal na preservação da ordem pública, com o incremento das atividades complementares da segurança privada. A discussão quanto à garantia dos interesses da sociedade perpassa pela proteção dos interesses públicos e privados.

No caso da segurança privada, há um incremento de suas atividades devido ao crescimento do crime organizado. Todavia, não se deve conceder, em princípio, que essas empresas, em razão do sucateamento da segurança pública, obtenham lucros atendendo a interesses pessoais ou de nichos mercadológicos, com o aval do Estado.

A segurança é dever do Estado e direito constitucional do cidadão, a preservação da boa ordem da coisa pública é o fator motivador da atuação da polícia, como um recurso da 
autoridade estatal contra perturbações ocasionadas pelas existências individuais. Em uma readequação do sentido da ordem pública, o Estado é chamado cada vez que houver um perigo, uma possibilidade de atentar-se à ordem pública.

No presente estudo, apresentam-se considerações sobre a ordem pública, com a associação à incolumidade das pessoas e patrimônio. Em seguida, descreve-se a legislação, as políticas e os órgãos que compõem a segurança pública e as atividades de segurança privada no Brasil. O Plano Plurianual de Ação (PPA) e o Plano Nacional de Segurança Pública e Defesa Social (PNSP) vigentes têm algumas características importantes no planejamento estatal sobre a segurança, que repercutem sobremaneira na economia do país (BRASIL, 2015, 2018b).

O objetivo geral do artigo é avaliar as políticas públicas referentes à segurança pública e segurança privada no Brasil. Para sua consecução, foram estabelecidos como objetivos específicos: a) levantar a previsão de políticas públicas no PPA e no PNSP, em especial aquelas de incentivo à execução das atividades de segurança privada no país; b) apresentar a legislação constitucional e infraconstitucional mais relevantes da segurança pública e privada no Brasil; c) levantar e consolidar dados oriundos do Departamento de Polícia Federal (DPF) referentes às empresas e pessoas empregadas nas atividades de segurança privada no Brasil; d) avaliar possíveis impactos à segurança pública quanto ao exercício das atividades da segurança privada sob o amparo de um planejamento estatal.

Assim, a questão formulada neste trabalho refere-se à existência, ou não, de um planejamento estatal que incentive a atividade de segurança privada e implique em um enfraquecimento da atividade de segurança pública no Brasil.

O método adotado é o qualitativo do tipo exploratório, com base em levantamento da legislação e políticas públicas vigentes sobre as atividades de segurança privada.

\section{ORDEM PÚBLICA}

A ordem pública, bastante evidente no Cap. III da Segurança Pública, especificamente no art. 144 da CRFB/88, permite "[...] que o intérprete ou o aplicador possam atribuir certo significado, mutável em função da valoração que se proceda diante dos pressupostos da norma" (CARVALHO FILHO, 2012, p. 54).

Filocre (2017) reforça esse entendimento de conceito jurídico indeterminado: 
A complexidade da noção de ordem pública viria de fato de nela ser compreendida não apenas a ordem material das ruas, mas ainda a manutenção de uma certa ordem moral, de modo a torna-la mais facilmente entendida, sentida, do que efetivamente definida, especialmente porque é uma noção que sofre variações no tempo e no espaço (FILOCRE, 2017, p. 56).

A terminologia jurídica da expressão ordem pública possui dois sentidos para Filocre (2017): a) o primeiro sentido corresponderia à designativa de parâmetros basilares de comportamento social, abarcando, em sentido amplo, entre outros, quaisquer relações morais com costumes morais, a família e a economia; há a divisão de ordem interna, como conjunto de normas que regem a sociedade, visando o bem-estar social, a ordem e os costumes no âmbito interno, e a ordem externa, como sendo as normas que regem as questões entre os diversos Estados; b) o segundo sentido teria o significado de clima de equilíbrio e paz indispensável à convivência coletiva diária.

Além de prover saúde, educação e outros serviços que garantam o bem-estar social, o Estado zela pela preservação do patrimônio dos cidadãos e sua integridade física. Essa legitimidade do governo depende de sua capacidade de manter a ordem entre os cidadãos nos territórios submetidos à sua autoridade (SAPORI, 2007).

Há um vínculo estreito entre Estado, governo, ordem pública e autoridade em situações de irrupção da ordem. E a eficiência estatal tem sido colocada a teste, não só no Brasil, mas tem todo o mundo. A percepção é que o governo, em alguns países e épocas distintas, utiliza institucionalmente o monopólio da violência física para manter-se em um status quo de arbitrariedade social institucionalizada, permanecendo, assim, em um Estado de exceção permanente.

Nessa linha de raciocínio, para Mendes (2016, p. 221), “[...] na segurança pública estão em embate os discursos que defendem a manutenção da ordem em contraponto ao paradigma da transformação social”, e a sensação de insegurança no contexto urbano provém de um controle de classes excluídas, o que provoca a manutenção da própria violência e "[...] a busca de meios de segurança privada e cobrança de aumento punitivo dos mecanismos estatais".

A capacidade dos órgãos públicos de manejarem os conflitos sociais derivados de comportamentos desviantes, através de mecanismos de controle social, é um grande desafio, não somente para as forças públicas do Estado, na seara da segurança pública, mas também, 
para as próprias forças armadas ao serem convocadas, quando a irrupção da ordem atinge níveis mais graves e intoleráveis.

Há um secular debate entre o público e o privado. Existe uma igualdade na garantia constitucional da defesa do interesse público e do privado, via de regra pela ponderação de interesses, em que o Princípio da Proporcionalidade tem fundamental relevância. Bobbio (1986) destaca que, nesse desencadear de relações sociais, há uma sociedade de iguais e uma sociedade de desiguais, que merece prudente reflexão:

\begin{abstract}
Sendo o direito um ordenamento de relações sociais, a grande dicotomia público/privado duplica-se primeiramente na distinção de dois tipos de relações sociais: entre iguais e entre desiguais. O Estado, ou qualquer outra sociedade organizada onde existe uma esfera pública, não importa se total ou parcial, é caracterizado por relações de subordinação entre governantes e governados, ou melhor, entre detentores do poder de comando e destinatários do poder de obediência, que são relações entre desiguais (BOBBIO, 1986, p. 15).
\end{abstract}

Em posição de complementariedade, as atividades de segurança privada acabam por atender à demanda emergente por segurança, também decorrente de momentos de crise e de uma criminalidade crescente e organizada, que não é exclusiva do Brasil.

Para Sapori (2007) os mecanismos de controle social são diversificados, pois

A criação da necessidade pela ordem pública é parte do processo de emergência de concepções de crime reconhecidas e categorizadas pelas autoridades públicas e por especialistas profissionais. Acompanha a expansão administrativa do Estado e sua paulatina aquisição do monopólio efetivo da força (SAPORI, 2007, p. 21).

$\mathrm{O}$ direito à segurança encontra-se no caput do art. $5^{\circ}$ da $\mathrm{CRFB} / 88$, enquanto relaciona-se a uma ideia de garantia individual, e no art. $6^{\circ}$ da CRFB/88, quando se aproxima da ideia de segurança pública (LENZA, 2011).

Valente (2017) considera a segurança como uma necessidade coletiva prestada regular e continuamente pelos órgãos e indivíduos da Administração Pública nos termos estabelecidos pela lei,

Socorrendo-nos da teoria das necessidades colectivas como fundo do interesse público [...], consideramos que a segurança é uma dessas necessidades colectivas, cuja satisfação regular e contínua deve ser provida pela actividade típica dos organismos e indivíduos da Administração Pública, nos termos estabelecidos pela legislação aplicável, devendo aqueles obter para o efeito os recursos mais adequados e utilizar as formas mais convenientes, quer sob direcção ou fiscalização 
do poder político e executivo, quer sob o controle dos tribunais (grifos do autor) (VALENTE, 2017, p. 125).

Modernamente, a atuação da polícia tem nova dimensão quanto à manutenção da ordem pública tradicional, antes baseada em conceitos como moralidade pública e perturbação da ordem, definidos pelas autoridades administrativas. Atualmente, há uma tendência de que a manutenção da ordem pública seja fundada especialmente na garantia estatal pautada na própria sociedade, ou seja, em sua organização e manifestação (FILOCRE, 2017). Ao Estado, portanto, cumpre proteger a sociedade de perigos ameaçadores de interesses coletivos de direitos fundamentais. Parece um avanço para que se evitem danos irreparáveis aos interesses e direitos na essência do Estado Democrático do Direito, evitandose possíveis excessos. Visível a intervenção do Estado na segurança pública, em diversas ocasiões e locais, pois “[...] o Estado tem o dever de atuar positivamente para gerar desenvolvimento e justiça social" (SUNDFELD, 2012, p. 57).

Em uma visão econômica relacionada à atividade de segurança e desenvolvimento, cediço que se a insegurança instalar em uma determinada região os investimentos serão remanejados para outras áreas que possuam perigos e riscos menores ao investidor. Nesse sentido, apropriadas as palavras de Nunes (2012, p.100): “[...] sem crescimento, a crise é inevitável; sem crescimento não se sai da crise". Atento à garantia dos direitos sociais conquistados, Roosevelt, citado por Nunes (2012, p. 105), alerta que o capital financeiro não pode dominar a política, pois se isto ocorrer seria "[...] mais perigoso do que confiar o governo do mundo ao "crime organizado" ".

O crime também provoca prejuízo financeiro local, contratos não são cumpridos e a instabilidade prevalece. Grau (2017), sobre essa busca pela segurança no cumprimento dos contratos, entende que a totalidade estrutural que constitui a ordem pública apresenta caracteres particulares de constância e estabilidade, sem as quais seria impossível esse cálculo racional de uma justiça e administração, que funcionem de forma a permitir um ambiente propício ao ganho e acumulação de capital.

\subsection{Segurança e Direito Econômico nos Estados e municípios}


Nesse contexto, apresenta-se um recorte da segurança pública nos municípios, em especial, que vêm sendo alvo de ataques de quadrilhas e bandos alcunhados de 'cangaço moderno'.

Os municípios devem pautar seu planejamento e rever, juntamente com o respectivo Estado e União, formas possíveis de legislar em Direito Econômico para reforçar as verbas destinadas à segurança pública local. Necessário a realização de um planejamento para apoio às atividades de segurança pública e privada locais para viabilizar a atuação (ou não) das prefeituras junto a esses órgãos e empresas, coordenadas por um Comitê de Segurança Pública local.

Embora a maior responsabilidade da segurança pública, atualmente, fique afeta aos Estados é necessário quebrar esse paradigma em tempos de crise. Dessa feita, parques municipais, praças, prédios e logradouros públicos, entre outros locais, podem ter um reforço na proteção preventiva patrimonial e da integridade das pessoas.

A parceria é uma necessidade, todavia, devem ser adotadas cautelas, a maioria na seara jurídica. Para a superação de uma crise econômica como a que se vive, o senso comum adquirido em debates públicos que mobilizam os cidadãos e a opinião pública é quase um dever, para que se encontrem soluções democráticas. Rodrigues e Serra $(2012$, p. 6) chamam a atenção para o debate e escrutínio público da economia: "Sim, a economia é política e deve estar, por esse motivo, sujeita ao debate e ao escrutínio democráticos. Reconhecê-los torna a análise dos problemas mais realista e as propostas de solução mais sensatas".

A Constituição da República de 1988 foi elaborada com um projeto constitucional com foco na dignidade humana e na afirmação dos direitos sócio econômicos, decorrente de vários acontecimentos políticos, sociais e econômicos.

Há que se considerar a ideologia constitucionalmente adotada na constituição econômica que se divide em: a) comandos capitalistas, previstos nos incisos II e IV do art. 170 da Constituição Federal/88, como, por exemplo, o direito de propriedade privada dos meios de produção e livre concorrência; b) em comandos socialdemocratas, exemplificativamente, a função social dos meios de produção; e c) em comandos nacionalistas, como o de garantia da soberania econômica nacional. Os comandos estão previstos no Capítulo VII da magna Carta, intitulado "Da Ordem Econômica e Financeira" (CLARK; CORRÊA; NASCIMENTO, 2017). 
A regência do mercado financeiro para a alocação dos recursos e a mercantilização dos direitos econômicos e sociais de maneira desregulamentada é uma realidade. Aludida transformação de bens comuns e serviços públicos, como educação, saúde, moradia, segurança, energia, entre outros, em mercados emergentes de forma desregulamentada ou com um mínimo de regulamentação é fato.

Para António José Avelãs Nunes (2012, p. 112) o estado capitalista “[...] é o estado garantidor no seu melhor, garantindo os interesses de comando da pequena elite do capital financeiro". Nesse entendimento, com a exclusão das minorias acentuam-se as desigualdades e incrementam a pobreza de milhões de pessoas.

De fato, o sistema de segurança no país, passa, necessariamente, pela demanda de um Estado forte, capaz de oferecer um mínimo de atendimento aos clamores dos cidadãos menos favorecidos - que não são poucos - na garantia de seus direitos fundamentais.

Especificamente a respeito dos municípios, Clark (2013) manifesta-se quanto à possibilidade legal dos entes municipais legislarem em Direito Econômico, o que se encaixa como uma proposta plausível por ocasião da revisão do marco legal da segurança, prestes a ser reformulado pelo governo federal:

\footnotetext{
Assim sendo, os Municípios brasileiros devem e podem legislar em Direito Econômico articulando-se, dentre outros (arts. 170, 173, 174, 175 da CF), os arts. 24, I e V com os art. 30, I e II da Constituição de 1988, agindo no domínio social e econômico a fim de efetivar os comandos constitucionais possibilitadores de transformar a nossa realidade perversa (CLARK, 2013, p. 433).
}

Poder-se-ia, ainda, acrescentar o inciso IX do art. 30 da CRFB/88, qual seja: “[...] promover a proteção do patrimônio histórico-cultural local, observada a legislação e a ação fiscalizadora federal e estadual”, além daqueles já citados (BRASIL, 1988).

A Lei do Plano Plurianual será a 'viga mestra' para a política econômica intervencionista do município de forma racional e eficaz (CLARK, 2001).

Pensar Direito Econômico, nas palavras de Grau (2017, p. 146), “[...] é pensar o Direito como um nível do todo social - nível da realidade, pois - como mediação específica e necessária das relações econômicas".

$\mathrm{O}$ art. 174 da Carta brasileira e o seu §1, dão oportunidade ao Estado para avançar em suas políticas públicas, junto ao domínio social e econômico do país. No dispositivo 
citado há a menção à atuação reguladora do Estado, que compreende o exercício das funções de incentivo, planejamento e fiscalização (GRAU, 2017).

Filocre (2017) afirma que o Brasil manteve-se num estágio pré-Estado social ao não efetivar ações sociais e econômicas concretas para a minoração da criminalidade. A crítica do autor é que o Estado brasileiro optou pela transferência da responsabilidade da Administração Pública para a lei penal. E, de fato, o país ainda é deficiente quanto a políticas efetivas na área de segurança, embora tenha havido considerável avanço nas últimas décadas são ainda necessárias mudanças para o controle da criminalidade.

\section{SEGURANÇA PÚBLICA}

O artigo 144 da CRFB/88 é o maior referencial sobre a segurança pública e apresenta o rol taxativo de órgãos que a compõem: polícia federal, polícia rodoviária federal, polícia ferroviária federal, polícia civil, polícias militares e corpos de bombeiros militares, além da possibilidade dos municípios em constituir guardas municipais, destinadas à proteção de seus bens, serviços e instalações, conforme dispuser a lei (BRASIL, 1988).

\subsection{Política de segurança pública}

\subsubsection{Plano Nacional de Segurança Pública e Defesa Social (PNSP)}

A Política Nacional de Segurança Pública para o período de 2018 a 2028 iniciou-se com a implantação do Sistema Único de Segurança Pública (SUSP), aprovado pelo Congresso Nacional depois de anos de estudo. Conforme dados do Plano Nacional de Segurança Pública (PNSP), os Estados com crises fiscais ao longo de décadas, arcaram em 2016 com 85\% dos gastos na área, em contraste com 9\% do governo federal (BRASIL, 2018b).

A União não tinha atribuições específicas para a segurança pública em nenhuma Constituição, desde 1824. E isso, mesmo com o Brasil tendo fronteiras com dez países, quatro deles reconhecidos mundialmente como produtores de drogas, colocou o País como o segundo 
mercado mundial consumidor de cocaína e derivados, atrás somente dos Estados Unidos da América (EUA), conforme Levantamento Nacional de Álcool e Drogas (LENAD) da Universidade Federal de São Paulo (UNIFESP) (D’ALAMA, 2012).

O governo do Presidente Michel Temer criou um ministério dedicado exclusivamente à segurança pública, com vistas a governança para enfrentamento ao crime organizado. Com o governo Bolsonaro, a aludida pasta ministerial foi encampada pelo Ministério da Justiça e da Segurança Pública, tendo como ministro o ex-juiz federal Sérgio Moro, com promessas de combate incisivo ao crime organizado. Inobstante ser recente a mudança da estrutura administrativa do Governo Federal, com redução do número de ministérios, há um redimensionamento do PNSP e a atuação do governo federal é um caminho sem volta. Alternativas trazidas para incrementar o aporte de recursos financeiros para a segurança pública, como, por exemplo, as verbas das loterias geridas pela Caixa Econômica Federal (CEF) são uma prova do sucateamento dos recursos públicos destinados ao incremento das políticas afetas à segurança pública ao longo das últimas décadas.

De acordo com o PNSP (BRASIL, 2018b) previu-se uma estimativa na ordem de um bilhão de reais somente para 2018, e em 2022 a cifra tem estimativa para chegar a 4,3 bilhões de reais de investimento. O I PNSP é uma resposta à criminalidade crescente e também uma necessidade do Brasil para cumprir os Objetivos do Desenvolvimento Sustentável (ODS), da Organização das Nações Unidas (ONU), que consolida 17 objetivos e 169 metas que 193 países acordaram, com vigência a partir de 2016. O aludido PNSP brasileiro tem como foco a consecução de onze objetivos principais, com uma mudança pretendida na governança da política nacional, fomentados com cofinanciamento e participação das unidades da federação por meio de planos locais de segurança pública e defesa social.

De acordo com o PNSP (BRASIL, 2018b), o governo federal, com um maior ou menor rigor técnico, tentou implementar ao longo das últimas décadas, cinco planos de segurança pública, quais sejam: a) 2000 - PNSP, cujo objetivo era articular ações de repressão e prevenção da criminalidade no país; b) 2003 - lançado o embrião do Susp, com a finalidade de definir competências e articular as ações das polícias e outras instituições do sistema de justiça criminal; c) 2004 - foi criada a Força Nacional de Segurança Pública, programa do Governo Federal que visa instrumentalizar o princípio da cooperação federativa na área de segurança pública; atua sob a coordenação da Senasp com a função de atender necessidades emergenciais dos Estados e do Distrito Federal, por meio de reforço de profissionais de 
segurança pública, com vistas a restaurar a ordem pública e a preservação da incolumidade das pessoas e do patrimônio; d) 2007 - criado o Programa Nacional de Segurança Pública (PRONASCI) que permitiu o financiamento de ações de outras instituições estaduais e municipais, desde que ligadas à área de prevenção à violência distribuindo recursos maiores do que o próprio Fundo Nacional de Segurança Pública; e) 2012 - lançado o Plano Brasil Mais Seguro, com objetivo geral de redução da criminalidade violenta no País; f) 2015 anunciado o Plano Nacional para Redução de Homicídios (PNRH); f) 2017 - anunciado o Plano Nacional de Segurança Pública, tendo por objetivos a redução de homicídios dolosos e feminicídios, a redução da violência contra a mulher, a racionalização e modernização do sistema penitenciário e o combate integrado à criminalidade organizada transnacional.

Com a criação do Ministério da Segurança Pública houve uma alteração na pauta da segurança pública no sentido de incluir ações de defesa social (BRASIL, 2018b). Entre os objetivos e estratégias a serem implementados mediante os programas temáticos há várias estratégias que necessitam de tecnologia para serem implementadas, como: câmeras de monitoramento, botão de pânico e outros dispositivos eletrônicos e sistemas informatizados. Este nicho tecnológico está bastante evidente na atividade de segurança privada, sobremaneira nos serviços de vigilância eletrônica, e, certamente, em breve haverá uma maior interligação entre os setores público e privado da segurança, embora os termos segurança privada e segurança eletrônica sejam distintos.

\subsubsection{Plano Plurianual de Ação (PPA)}

No conteúdo do PPA de 2016-2019 há a proposta de "Fortalecimento das instituições públicas, com participação e controle social, transparência e qualidade na gestão" (BRASIL, 2015, p. 1381). Para a superação dos desafios compreendidos em cada Eixo Estratégico é proposto um conjunto de diretrizes que norteiam as principais agendas para o período, entre as quais há a seguinte que se relaciona diretamente com este estudo: "Fortalecimento da segurança pública e redução de homicídios, com integração de políticas públicas entre os entes federados, controle de fronteiras e promoção de uma cultura de paz” (BRASIL, 2015, p. 1381).

O PPA não trata especificamente de questões afetas à segurança privada, mas na área da segurança pública dá destaque ao Programa de Justiça, Cidadania e Segurança Pública, 
para o qual foram previstos recursos de 8,3 milhões de reais, ressaltando as seguintes metas: reduzir em $15 \%$ o número de homicídios; reduzir o número de mortos em acidentes em rodovias federais de 98 para 80 a cada um milhão de veículos da frota nacional; implantar Centros Integrados de Comando e Controle em todas as capitais; promover a redução do número de pessoas presas; e reduzir o grau de desigualdade de acesso à Justiça por Estado (BRASIL, 2015).

\section{SEGURANÇA PRIVADA}

Atualmente, o marco legal da segurança privada engloba leis, decretos e portarias, além de pareceres sobre matérias específicas: a) Lei $\mathrm{n}^{\circ}$ 7.102, de 20 de junho de 1983, que dispõe sobre segurança para estabelecimentos financeiros, estabelece normas para constituição e funcionamento das empresas particulares que exploram serviços de vigilância e de transporte de valores e dá outras providências; b) Decreto $n^{\circ}$ 89.056, de 24 de novembro de 1983, com as alterações do Decreto $\mathrm{n}^{\circ} 1.592$, de 10 de agosto de 1985 , que regulamenta a Lei $\mathrm{n}^{\mathrm{o}} 7.102$, de 20 de junho de 1983, que dispõe sobre segurança para estabelecimentos financeiros, estabelece normas para constituição e funcionamento das empresas particulares que exploram serviços de vigilância e de transporte de valores e dá outras providências; c) Portaria $\mathrm{n}^{\mathrm{o}}$ 2.494, de 3 de setembro de 2004, do Ministério da Justiça , que cria a Comissão Consultiva para Assuntos de Segurança Privada; d) Lei $n^{\circ} 10.826$, de 22 de dezembro de 2003, que dispõe sobre registro, posse e comercialização de armas de fogo e munição, sobre o Sistema Nacional de Armas (SINARM), define crimes e dá outras providências.

$\mathrm{O}$ arcabouço jurídico do marco legal da segurança privada é extenso, incluindo a Lei $n^{\circ}$ 9.017, de 1995; a Lei $n^{\circ} 11.718$, de 2008; a Lei $n^{\circ} 13.654$, de 2018; a Lei 8.863, de 1994; Medida Provisória $\mathrm{n}^{\mathrm{o}}$ 1.184-23, de 2001, entre outros instrumentos jurídicos que trazem relação com as atividades em espeque.

Uma das mais importantes legislações que regulamenta as atividades de segurança privada é a Portaria $n^{0} 3.233 / 2012$, que dispõe sobre as normas relacionadas às atividades de segurança privada e prevê, expressamente, uma política de estímulo ao crescimento das empresas que atuam no setor.

CAPÍTULO I - DAS DISPOSIÇÕES PRELIMINARES

Art. $1^{\circ}$ A presente Portaria disciplina as atividades de segurança privada, armada ou 
desarmada, desenvolvidas pelas empresas especializadas, pelas empresas que possuem serviço orgânico de segurança e pelos profissionais que nelas atuam, bem como regula a fiscalização dos planos de segurança dos estabelecimentos financeiros.

$\S 1^{\circ}$ As atividades de segurança privada serão reguladas, autorizadas e fiscalizadas pelo Departamento de Polícia Federal - DPF e serão complementares às atividades de segurança pública nos termos da legislação específica.

$\S 2^{\circ}$ A política de segurança privada envolve a Administração Pública e as classes patronal e laboral, observando os seguintes objetivos:

I - dignidade da pessoa humana;

II - segurança dos cidadãos;

III - prevenção de eventos danosos e diminuição de seus efeitos;

IV - aprimoramento técnico dos profissionais de segurança privada; e

V - estímulo ao crescimento das empresas que atuam no setor (BRASIL, 2012).

$\mathrm{O} \S 3^{\circ}$ do art. $1^{\circ}$ da referida Portaria elenca as atividades de segurança privada, quais sejam: vigilância patrimonial, transporte de valores, escolta armada, segurança pessoal e curso de formação (BRASIL, 2012).

O Estado pode intervir no domínio econômico para assegurar a todos uma convivência digna, de acordo com os ditames da justiça social, certamente com planos democráticos e articulados, podendo tanto restringir quanto incentivar atividade econômica privada (CLARK; CARVALHO; SEVERO E SOUZA, 2014). Aludida intervenção do Estado no domínio econômico, então, pode ser feita mediante a técnica do planejamento. "Nas modalidades de Planejamento democrático a empresa privada encontra outras condições para a obtenção de lucros, inclusive nas medidas de estímulo do Estado" (SOUZA, 2005, p. 397).

Para Zanetic (2005) a expansão dos serviços particulares de segurança, verificada em diversos países a partir de meados do século $\mathrm{XX}$, traz à tona questões relevantes como a responsabilidade do Estado sobre a segurança e a necessidade de aprimoramento dos mecanismos de regulação e controle pelos órgãos responsáveis.

Verificou-se que há poucas referências às atividades de segurança privada no PNSP e no PPA vigentes. Assim, efetivamente há no PNSP, no Objetivo 10 - Aprimorar os mecanismos de prevenção e repressão aos crimes violentos patrimoniais, uma estratégia, de número 7.10.6 (BRASIL, 2018b):

7.10.6 - Reformular o marco legal da segurança privada no Brasil, revisando as condições de operação, relação com servidores da segurança pública e os mecanismos de prestação de contas, bem como aumentar a capacidade de fiscalização do Estado sobre este setor (BRASIL, 2018b). 
O Estado, ao mesmo tempo em que deseja revisar as condições de funcionamento da segurança privada no Brasil, permeando sua atuação com a segurança pública, quer incrementar os mecanismos de controle e fiscalização da atuação dessas empresas. Pereira (2018) entende que o Estado, ao não oferecer um serviço de segurança com eficiência, faz com que outros executores surjam, sob o manto do Princípio da Complementariedade, e entende que esse mesmo Estado deve agir contra o executor do serviço, sob pena da prática de prevaricação, nos moldes do art. 319 do Código Penal brasileiro. Apresenta o caso da Guarda Municipal, que, ao executar patrulhamento ostensivo, teve suas ações de policiamento ostensivo contestadas em Ação Direta de Inconstitucionalidade e acrescenta: "O que dirá, pois, da atuação de vigilantes privados, semifardados e em veículos identificáveis" (PEREIRA, 2018).

Há de se anuir outros apontamentos de Pereira (2018), como, por exemplo, a responsabilidade civil objetiva prevista no art. 37, § 6, pela Guarda Municipal no caso exemplificado acima que atua além de sua responsabilidade constitucional prevista no art. 144, $\S 8$ da CRFB/88. E, ainda, usurpa a função própria do Estado, no que também se enquadraria o vigilante privado, por exemplo, que atua como se policial fosse.

Valente (2017) entende que a segurança é função ou tarefa fundamental do Estado, a quem o cidadão confiou sua liberdade para gerir em prol da edificação do bem individual e supra-individual. Adverte, ainda, quanto a ascendência do sentimento de insegurança (e segurança) em prol do crescimento da 'complementariedade', que acaba sendo "[...] subsidiariedade da segurança individual - serviço licenciado de autoproteção privada - ou da segurança promovida por pessoas colectivas - prestação de serviços de segurança por empresas de segurança detentoras de Alvará" (grifos do autor) (VALENTE, 2017, p. 126). E critica essa transferência de ideia de proteção do Estado para o particular, pois o cidadão entregou uma parcela de sua liberdade para o proteger:

Esta solução (de despublicização de uma actividade inata de interesse público) descredibiliza a confiança do cidadão depositada no Estado, gera uma desigualdade na fruição real do bem segurança- nem todos têm posses para se socorrerem de serviços de autoprotecção ou de serviços prestadores de segurança -, e enfraquece o Estado no acesso à informação do mundo do crime de massa e do crime organizado. Há assim, um perigo para o Estado de direito democrático com a promoção da destatalização da função de segurança (grifos do autor) (VALENTE, 2017, p. 126). 
A Polícia Federal ao regular, autorizar e fiscalizar as atividades de segurança privada apresentou um relatório consolidado das empresas que atuam no setor, bem como de pessoas envolvidas nessas atividades, que foram consolidados na Tabela 1.

Tabela 1 - Consolidação dos relatórios totalizados de empresas de segurança privada e pessoas com vínculo ativo - Brasil, novembro 2018

\begin{tabular}{|c|c|c|c|c|}
\hline $\begin{array}{l}\text { Unidade da } \\
\text { Federação }\end{array}$ & $\begin{array}{l}\text { Vigilância } \\
\text { patrimonial }\end{array}$ & Escolta armada & $\begin{array}{c}\text { Transporte de } \\
\text { valores }\end{array}$ & Total de pessoas \\
\hline Acre & 12 & 6 & 7 & 1.780 \\
\hline Alagoas & 22 & 11 & 5 & 5.582 \\
\hline Amazonas & 44 & 21 & 19 & 8.883 \\
\hline Amapá & 13 & 4 & 2 & 2.409 \\
\hline Bahia & 173 & 63 & 28 & 33.245 \\
\hline Ceará & 77 & 21 & 10 & 17.932 \\
\hline Distrito Federal & 78 & 23 & 7 & 21.185 \\
\hline Espírito Santo & 47 & 26 & 11 & 11.117 \\
\hline Goiás & 93 & 32 & 13 & 18.191 \\
\hline Maranhão & 57 & 18 & 10 & 11.129 \\
\hline Minas Gerais & 181 & 81 & 50 & 34.535 \\
\hline Mato Grosso do Sul & 45 & 12 & 9 & 4.823 \\
\hline Mato Grosso & 56 & 25 & 15 & 7.041 \\
\hline Pará & 72 & 33 & 19 & 12.773 \\
\hline Paraíba & 42 & 13 & 9 & 6.881 \\
\hline Pernambuco & 74 & 28 & 11 & 21.297 \\
\hline Piauí & 31 & 12 & 14 & 4.781 \\
\hline Paraná & 226 & 89 & 22 & 26.851 \\
\hline Rio de Janeiro & 208 & 87 & 21 & 50.874 \\
\hline Rio G. do Norte & 40 & 12 & 6 & 6.987 \\
\hline Rondônia & 23 & 4 & 7 & 5.117 \\
\hline Roraima & 5 & 3 & 2 & 902 \\
\hline Rio Grande do Sul & 157 & 57 & 28 & 30.694 \\
\hline Santa Catarina & 153 & 55 & 18 & 20.858 \\
\hline Sergipe & 25 & 8 & 4 & 6.294 \\
\hline São Paulo & 597 & 263 & 69 & 151.584 \\
\hline Tocantins & 19 & 7 & 5 & 2.061 \\
\hline Total & 2.570 & 1.014 & 421 & 525.806 \\
\hline
\end{tabular}

Fonte: Brasil, 2018a.

Esses números permitem uma noção da magnitude do efetivo de pessoas empregadas nas atividades de segurança privada, que, juntamente com os demais órgãos federais, estaduais e municipais de segurança pública, de forma planejada e coordenada, podem oferecer auxilio no combate à criminalidade violenta no país.

Se a intenção é preservar a incolumidade das pessoas e o patrimônio, com um processo de seleção bem feito, formação, aperfeiçoamento e treinamento adequado para o exercício das funções afetas às atividades de segurança privada, certamente pode-se agregar as ações e operações no combate ao crime, minimizando seus perigos iminentes. $\mathrm{O}$ sistema de 
inteligência com tecnologia, equipamentos, viaturas e armamentos apropriados a cada unidade federativa são necessários, senão indispensáveis. A importância de um bom planejamento estatal influenciará o resultado final que se busca no alcance e manutenção da paz social, mesmo que em longo prazo.

\section{CONCLUSÃO}

De todo o exposto, não se comprovou concorrência das atividades de segurança privada com as dos órgãos de segurança pública, mesmo porque há a possibilidade até de serem incursos em crime de usurpação pública aqueles agentes que exorbitarem suas funções, adentrando nas missões constitucionais dos respectivos órgãos.

Embora exista uma legislação específica para as atividades de segurança privada como complementar a atividade de segurança pública, a Polícia Federal tem o controle das atividades de segurança privada no país. Todavia, esse controle cinge-se às empresas regulares e, infelizmente, é fato a existência de empresas clandestinas e pessoas despreparadas que se aventuram pelo setor de segurança. O PNSP vigente sinaliza a preocupação em revisar as condições de operação, relação com servidores da segurança pública e os mecanismos de prestação de contas e fiscalização sobre o setor.

Isto posto, com as cautelas de praxe a serem avaliadas para que não haja atuação à margem da lei, os gestores da segurança pública, conscientes de que são parcos os recursos disponíveis ao Estado podem, senão devem, incrementar políticas de cooperação com as atividades de segurança privada para auferir um combate eficaz ao crime organizado semfronteiras.

Não parece factível desperdiçar o apoio da segurança privada à segurança pública e, por isso, desde que devidamente controlada pelo Estado, é válida a complementariedade das atividades privadas de segurança em prol da segurança pública, pelo menos à primeira vista. Também não há dúvidas da necessidade de intervenções do Estado quanto à legislação penal e processual penal vigentes no país, minimizando-se os casos de reincidência criminal e a sensação de impunidade, pois a sensação de insegurança e perigos diversos que não sejam da seara pública também fomentam o crescimento de atividades privadas de segurança.

O Direito Econômico surge como uma proposta viável, que está à disposição do Estado há muito tempo, enquanto agente normativo e regulador, realizando atividades de 
fiscalização, incentivo e planejamento da economia. A proposta dos municípios em legislar em Direito Econômico, atuando em seu domínio econômico e social certamente auxiliará o sistema de segurança como um todo. Devem-se buscar alternativas para que haja uma gestão conjunta, com um planejamento estatal eficiente, utilizando de forma inteligente o Direito para os fins sociais que almeja a população. Elaborar um Plano Plurianual local é a 'viga mestra' para uma proposta jurídica interessante para a intervenção no domínio econômico e social, desde que democraticamente discutido com os cidadãos.

Em que pesem as alternativas trazidas à pauta pela segurança privada, o texto Constitucional está claro quanto ao direito à segurança do cidadão e negá-lo no ensejo de ver atendido o poder econômico privado, é deixar ao largo toda a luta social conquistada em prol da dignidade humana.

\section{REFERÊNCIAS}

BOBBIO, Norberto. Estado, governo, sociedade: por uma teoria geral da política. Trad. Marco Aurélio Nogueira. Rio de Janeiro: Paz e Terra, 1986.

BRASIL. Constituição (1988). Constituição da República Federativa do Brasil, 1988. Disponível em: http://www.planalto.gov.br/ccivil_03/constituicao/constituicaocompilado.htm. Acesso em: 3 jan. 2019.

BRASIL. Ministério da Justiça. Polícia Federal. Decreto $n^{\circ} 3.233$, de 10 de dezembro de 2012. Dispõe sobre as normas relacionadas às atividades de Segurança privada. Disponível em: http://www.pf.gov.br/servicos-pf/seguranca-privada/legislacao-normas-eorientacoes/portarias/portaria-3233-2012-2.pdf/view. Acesso em: 3 jan. 2019.

BRASIL. Ministério da Justiça e Segurança Pública. Polícia Federal. Relatórios de empresas por órgão. 2018a. Disponível em: http://www.pf.gov.br/. Acesso em: 3 jan. 2018.

BRASIL. Ministério do Planejamento, Orçamento e Gestão. Plano Plurianual de Ação 20162019. Brasília: Ministério do Planejamento, Orçamento e Gestão, 2015.

BRASIL. Ministério da Segurança Pública. Plano Nacional de Segurança Pública e Defesa Social 2018-2028. Brasília: Ministério da Segurança Pública, 2018b.

CARVALHO FILHO, José dos Santos. Manual de direito administrativo. 25. ed. rev., ampl. e atual. até a Lei n. 12.587, de 3.1.2012. São Paulo: Atlas, 2012. 1250p.

CLARK, Giovani. O município em face do Direito Econômico. Belo Horizonte: Del Rey, 2001. 266p. 
CLARK, Giovani. A ADI 1950: o Voto Aula do Direito Econômico. In: COSTA, José Augusto Fontoura; ANDRADE, José Mania Arruda de; MATSUO, Alexandra Mery Hansen (Orgs.). Direito: teoria e experiência. Estudo em homenagem a Eros Roberto Grau. São Paulo: Malheiros, 2013. Tomo I. p. 429-451.

CLARK, Giovani; CARVALHO, Antônio Roberto Winter; SEVERO E SOUSA, Simone Letícia. Cap VII - A responsabilidade civil do Estado por intervenção no domínio econômico. In: FARIA, Edimur Ferreira de (Coord.). Responsabilidade civil do Estado: no ordenamento jurídico atual. Belo Horizonte: Del Rey, 2014. p. 181-203.

CLARK, Giovani; CORRÊA, Leonardo Alves; NASCIMENTO, Samuel Pontes do. A constituição econômica entre a efetivação e os bloqueios institucionais. Revista da Faculdade de Direito da UFMG, n. 71, p. 677-700, jul./dez. 2017.

D'ALAMA, Luna. Brasil é o $2^{\circ}$ consumidor mundial de cocaína e derivados, diz estudo. 5 set. 2012. Disponível em: http://g1.globo.com/ciencia-e-saude/noticia/2012/09/brasil-e-osegundo-maior-consumidor-de-cocaina-e-derivados-diz-estudo.html. Acesso em: 3 jan. 2019.

FILOCRE, Lincoln D’Aquino. Direito policial moderno: polícia de segurança pública no direito administrativo brasileiro. São Paulo: Almedina, 2017. 187p.

GRAU, Eros Roberto. A ordem econômica na Constituição de 1988: (interpretação e crítica). 18 ed. rev. ampl. São Paulo: Malheiros, 2017. 384p.

LENZA, Pedro. Direito Constitucional Esquematizado. 15. ed. ver. atual. e ampl. São Paulo: Saraiva, 2011. 1196p.

MENDES, Kíssila Teixeira. Segurança pública e lógica neoliberal: a realidade brasileira. Ideias - Rev. Inst. Filos. Ciênc. Hum. UNICAMP, v. 7, n. 1, p. 203-26, jan./jul. 2016.

NUNES, António José Avelãs. A crise atual do capitalismo: capital financeiro, neoliberalismo, globalização. São Paulo: Revista dos Tribunais, 2012. (Coleção Direito Europeu; v. 3).

PEREIRA, Jeferson Botelho. Falência das Segurança Pública. Então a lei autoriza segurança privada em vias públicas? Pode isso? Mar. 2018. Disponível em:

https://jus.com.br/artigos/64816/falencia-da-seguranca-publica-entao-a-lei-autorizaseguranca-privada-em-vias-publicas-pode-isso. Acesso em: 12 jan. 2019.

RODRIGUES, João. SERRA, Nuno. Prefácio. In: ASKENAZY, Philippe. Manifesto dos economistas aterrados: crise e dívida na Europa: 10 falsas evidências, 22 medidas em debate para sair do impasse. Trad. Nuno Serra. Lisboa: Actual, 2012. p. 6-7.

SAPORI, Luís Flávio. Segurança pública no Brasil: desafios e perspectivas. Rio de Janeiro: FGV, 2007. 208p.

SOUZA, Washington Peluso Albino de. Primeiras linhas de Direito Econômico. 6. ed. São Paulo. Ltr, 2005. 606p. 
SUNDFELD, Carlos Ari. Fundamentos de Direito Público. 5. ed. São Paulo: Malheiros, 2012. 189p.

VALENTE, Manuel Monteiro Guedes. Teoria Geral do Direito Policial. 5. ed. Coimbra: Almedina, 2017. 757p.

ZANETIC, André. A questão da segurança privada: estudo do marco regulatório dos serviços particulares de segurança. 2005. 117f. Dissertação (Mestrado em Ciências Políticas) - Universidade de São Paulo, São Paulo, 2005. 